in areas such as vision, language and complex logic puzzles - territories in which humans are expected to retain an edge on computers for some time to come.

David Anderson, a UCB computer scientist and the founder of BOINC, admits that the approach is still a long way from becoming mainstream. For many sceptical scientists, he says, "there's this idea that they're giving up control somehow, and that their importance would be diminished".

But advocates of distributed thinking, such as François Grey, a physicist at CERN, Europe's particle-physics centre near Geneva, have few doubts. Last July, Grey helped to establish the Citizen Cyberscience Centre in Geneva, which aims to promote distributedthinking projects, especially in the developing world. Grey is currently setting up distributed-computing projects in China. And he has helped to organize a workshop to be held in London this September to encourage scientists to adopt the new approaches.

"The whole field has a funny image, that it is just for fun or for PR," says Grey. "That's what we have to break through."

\section{The eye of the beholder}

Andrew Westphal, a UCB physicist, started on the road to distributed thinking almost two decades ago, when he was a lead investigator on a cosmic-ray experiment called TREK.

TREK consisted of specially designed glass plates mounted on the outside of the Russian space station Mir in 1991. Cosmic-ray particles pelting the glass left microscopic traces that were revealed by chemical etching after the TREK detector had returned to Earth in 1995. To find those traces, Westphal automatically scanned and recorded images of the plates using a microscope. But image-recognition

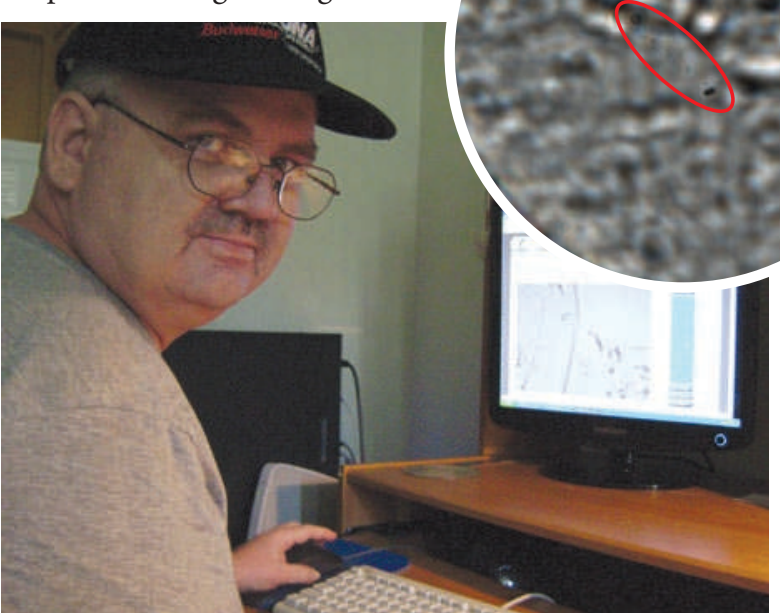

Non-scientist Bruce Hudson found the first dust particles from NASA's Stardust mission, naming them Orion (inset) and Sirius. software wasn't good enough to identify the tracks, so Westphal found himself staring at image after image, counting the tracks by eye. It was excruciating, he recalls. "Despite your best efforts, your mind wanders. You start to think about lunch or whatever."

That reality was on Westphal's mind when he joined NASA's Stardust mission, which was launched in 1999 to collect samples of a comet and return them to Earth. Westphal's focus was not on the comet itself, but on a collecting tray that was exposed to space during the years of cruising required to get there. He and his team were confident that 100 or so microscopic pieces of interstellar dust would burrow into the tray's aerogel, a wispy material designed to decelerate and capture the dust without damaging it. But again, the challenge was to find those particles.

Unfortunately, that task made TREK look easy. After the spacecraft's sample-return capsule fell to Earth in January 2006, Westphal reused the automatic imaging microscope from TREK to create 1.6 million images of the aerogel. He estimated that it would take a century for one person to peruse them all. So the following August, Westphal and his team launched Stardust@home, a continuing project that enlists the pattern-recognition abilities of thousands of volunteer 'dusters'.

Although the '@home' name pays homage to BOINC volunteer computing programs, Stardust@home is one of the pioneering distributed-thinking projects. As such, it faced plenty of early hurdles. For example, the dusters had to be given lessons on how to avoid being fooled by cracks in the brittle aerogel or by particles of Earth dust that had embedded in the aerogel from the start. Only some of the volunteers worked diligently. Others quickly slacked off. And still others tried to cheat, just flipping through as many images as possible to rise to the top of a scorecard put in place as an incentive.

Westphal, working together with Anderson, realized that they would have to calibrate their volunteers just as they would any instrument. They had to find ways to assign a skill level to each volunteer; to assess how that skill level changes with time; and to

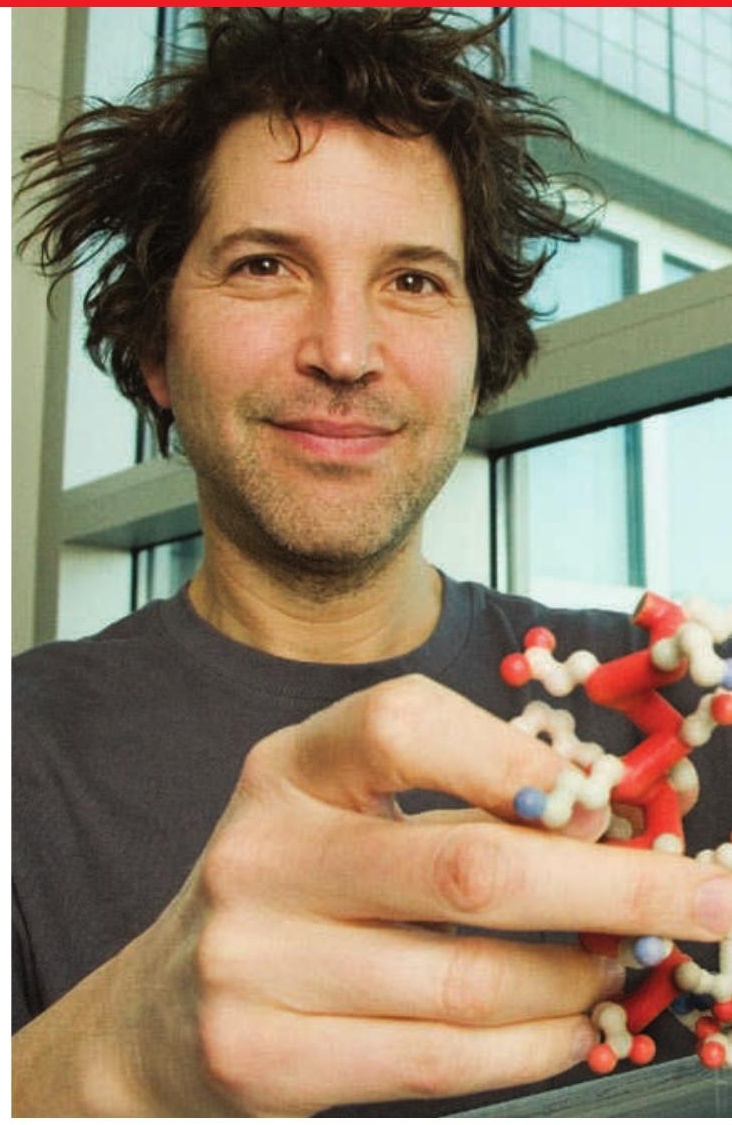

David Baker's online game Foldit uses the basic problem-solving skills of volunteers to help solve three-dimensional protein structures.

determine how many volunteers had to reach the same conclusions about an image before a result could be believed.

\section{Cosmic stardust agents}

For Bruce Hudson, a resident of Midland, Ontario,Stardust@home was a perfect way to fill the long days. In 2003, he had a stroke that rendered the right side of his body mostly useless. Even computer games weren't much fun. But somehow, the endless microscope photos of aerogel were enthralling. "I've always liked the stars and the planets and all that kind of stuff," says Hudson, who previously worked as a groundskeeper for a Catholic shrine. $\mathrm{He}$ estimates that he spent as much as 15 hours a day on the project.

His hard work paid off. In March 2010, at the Lunar and Planetary Science Conference in Houston, Texas, Westphal announced that Hudson had found the first probable piece of stardust - actually a pair of particles in the same track (see Nature doi:10.1038/news.2010.106; 2010). "I still can't believe it," says Hudson, who named the particles Orion and Sirius. Westphal is already using the unique characteristics of Orion and Sirius to calibrate the expectations of a new generation of Stardust volunteers.

Meanwhile, Anderson is reprising what he did with BOINC by generalizing the Stardust@home software, so that it can be used by scientists for other distributed-thinking projects. He calls the result Bossa, which doesn't stand for anything. "At some point, I 
